\title{
Presentation and detection of breast cancer in seven patients with subglandular augmentation mammaplasty
}

\author{
Mitchell H Brown BSC MD FRCSC, John L Semple BSC MD MSC FRCSC, FACS \\ Division of Plastic Surgery, Women's College Hospital, University of Toronto, Toronto, Ontario
}

\begin{abstract}
MH Brown, JL Semple. Presentation and detection of breast cancer in seven patients with subglandular augmentation mammaplasty. Can J Plast Surg 1995;3(1):25-29. More than two million women in the United States have undergone augmentation mammaplasty. A woman's lifetime risk of developing breast cancer is nearing 1 in 9 , which means that over 200,000 augmented women may go on to develop breast cancer. Several studies have implied that women who develop breast cancer following augmentation mammaplasty are less likely to present with occult disease. They present more often with a palpable mass and are more likely to have involved axillary nodes. This paper looks at seven patients who developed breast cancer in the presence of subglandular mammary implants. Mode of presentation, pathologic type, nodal status, relationship of the tumour to the breast capsule and surgical treatment will be discussed. Consideration should be given to recommending against augmentation mammaplasty in those women with a strong family history of breast cancer or other significant risk factors. Women who undergo breast augmentation should be informed that the detection of occult disease with mammography may be more difficult following augmentation. The prognostic significance of this has yet to be fully determined.
\end{abstract}

Key Words: Augmentation mammaplasty, Breast augmentation, Breast cancer

\section{Présentation et dépistage du cancer du sein chez sept patientes ayant subi une addition mammaire sous-glandulaire}

RÉSUMÉ : Plus de 2 millions de femmes aux États-Unis ont subi une addition mammaire. Le risque qu'une femme développe un cancer du sein au cours de sa vie est près de 1 sur 9 , ce qui signifie que plus de 200000 femmes ayant subi cette intervention peuvent éventuellement développer un cancer du sein. Plusieurs études ont suggéré que les femmes qui développent un cancer du sein après une addition mammaire sont moins susceptibles de souffrir d'une forme occulte de la maladie. Le plus souvent, elles présentent une masse palpable et les ganglions axillaires sont plus susceptibles d'être atteints. Cet article se penche sur sept patientes qui ont développé un cancer du sein alors qu'elles avaient des implants mammaires sous-glandulaires. Le mode de présentation, le type pathologique, le statut des ganglions, le rapport tumeur/capsule mammaire et le traitement chirurgical seront abordés. L'addition mammaire est relativement contre-indiquée chez les femmes qui ont des antécédents familiaux lourds de cancer du sein ou d'autres facteurs de risque importants. Les femmes qui subissent une addition mammaire devraient être informées que le dépistage de la maladie occulte par mammographie peut être plus difficile après l'intervention. La portée pronostique de ce phénomène reste à déterminer.

A ugmentation mammaplasty has been one of the most common surgical procedures performed in North America. Despite a recent decline in the yearly rate of augmentations, it is estimated that more than two million women in the United States have undergone breast augmentation (1). Several studies have shown that augmentation with silicone implants does not cause breast cancer (2-5). We know, however, that approximately $11 \%$ of women will develop breast

Presented at the 46th Annual Meeting of the Canadian Society of Plastic Surgeons, London, Ontario, 1992

Correspondence and reprints: Dr Mitchell H Brown, c/o Dr John Semple, Women's College Hospital, Burton Hall, 60 Grosvenor Street, 2nd Floor, Toronto, Ontario M5S 1B6. Telephone (416) 323-6115,

Fax (416) 921-4275 carcinoma during their lifetime (6). As the age of patients with breast implants increases, we can expect a rise in the incidence of breast cancer following augmentation mammaplasty.

The most favourable outcome for breast cancers are occult lesions found in asymptomatic women undergoing screening mammography (7-10). Ideally, we would therefore like to be able to insert implants without decreasing our ability to detect occult malignancies. Capsule contractures have been shown to occur around a breast implant with an incidence as high as $74 \%$ (11). The presence of a contracture can interfere with both patient self-examination and examination by the physician. Compression mammography becomes increas- 
ingly difficult and displacement mammography almost impossible. It has therefore been suggested that augmented patients, especially those with capsular contractures, may have a more advanced disease at the time of diagnosis (12.13). This could be manifest by an increased percentage of invasive lesions and involved axillary lymph nodes $(12,13)$. Leibman (14), however, has stated that with modified position views on mammography and the addition of sonography when necessary, patients with implants who develop cancer do not necessarily present at a more advanced stage. Other modalities of imaging the augmented breast such as magnetic resonance imaging have also been reported (15).

This article reviews seven patients seen and treated at our institution, who had developed breast cancer following augmentation mammaplasty. Mode of presentation, pathologic type, nodal status, relationship of the tumour to the breast capsule and surgical treatment will be stressed.

\section{CASE 1}

Ms DB presented at age 47 with a palpable mass in the right breast. She had had subglandular augmentation with Cronin implants 14 years earlier. At the time of presentation, there was a firm mass in the right upper outer quadrant and a palpable node in the right axilla. The patient had Baker II capsules. Subsequently a mammogram was performed which was limited due to the contractures (the patient had difficulty abducting her right arm). The mammogram was reported as normal. A lumpectomy and axillary node dissection was performed. Grossly, the tumour was anterolateral to the implant and did not approach the capsule. Histologically, there was a $1.1 \mathrm{~cm}$ infiltrating ductal carcinoma with two of nine positive nodes. There was no evidence of extranodal spread.

\section{CASE 2}

Ms JR presented at age 52 with a palpable mass in the right breast. She had had subglandular augmentation with Klein implants seven years earlier. At the time of presentation, there was a firm palpable mass in the lateral aspect of the right breast. There was no palpable axillary adenopathy. The patient's mother had been treated for breast cancer. The patient was treated in 1980 with a simple mastectomy. Histologically, this was an infiltrating ductal carcinoma with lymphatic involvement. Five months later the patient presented with a mass in the right axilla. An axillary node dissection was performed and five of 10 nodes were positive for malignancy.

\section{CASE 3}

Ms RP presented at age 49 with a palpable mass in her left breast. She had had subglandular augmentation 12 years earlier. At the time of presentation, there was a firm mass in the upper inner quadrant of the left breast. There was no palpable axillary adenopathy. Needle aspiration for cytology was positive for malignant cells and a lumpectomy and axillary node dissection was performed. Histologically, there was an infiltrating ductal carcinoma with axillary nodes negative for malignancy. Four years later, the patient presented with a palpable mass in the right breast. A mammogram two months earlier had been reported as being normal. A lumpectomy and axillary node dissection was performed and the pathology revealed an infiltrating ductal carcinoma with axillary nodes negative for malignancy. Both lesions were clearly separate from the breast capsules.

\section{CASE 4}

Ms AS presented at age 50 with a palpable mass in her right breast. She had had subglandular augmentation 25 years earlier. At the time of presentation, there was a firm, mobile mass superior to the areola of the right breast. There was no palpable axillary adenopathy. The patient underwent a lumpectomy and axillary node dissection. Histologically, the tumour was an infiltrating ductal carcinoma with axillary nodes negative for malignancy.

\section{CASE 5}

Ms AK presented at age 47 with a palpable mass in the left breast. She had had subglandular augmentation performed 18 years earlier. At the time of presentation, there was a firm mass deep to the left nipple. There was no palpable axillary adenopathy. A biopsy revealed infiltrating ductal carcinoma and a modified radical mastectomy was performed. Axillary nodes were negative for malignancy. Four years later, the patient was admitted for an unrelated problem. Preadmission chest radiograph revealed several lesions which were then biopsied. These proved to be metastatic adenocarcinoma. Despite treatment with radiation and chemotherapy, the patient died one year later.

\section{CASE 6}

Ms HE presented at age 42 with a palpable mass in the left breast. She had had subglandular augmentation 15 years earlier. At the time of presentation, there was a firm palpable mass in the lateral aspect of the left breast. A lumpectomy was performed which revealed a focus of infiltrating ductal carcinoma. The patient was followed up with one month of radiation therapy. Five years later, the patient complained of pain in the left breast. A mammogram was performed which showed an area with 'suspicious changes'. Needle biopsy was nondiagnostic, and after an open biopsy revealed infiltrating ductal carcinoma, a modified radical mastectomy was performed. Axillary nodes were negative for malignancy but silicone particles with a surrounding giant cell reaction could be identified. The tumour was noted to be growing in a stellate fashion along the breast capsule but no invasion into the capsule was demonstrated.

\section{CASE 7}

Ms MC presented at age 48 with a lesion noted on routine mammography (Figure 1). She had had subglandular augmentation 17 years earlier. At the time of presentation, there was no palpable lesion and no palpable axillary adenopathy. Using localization techniques, a biopsy was performed which revealed intraductal carcinoma with clear margins. A repeat mammogram two months later showed that there were 

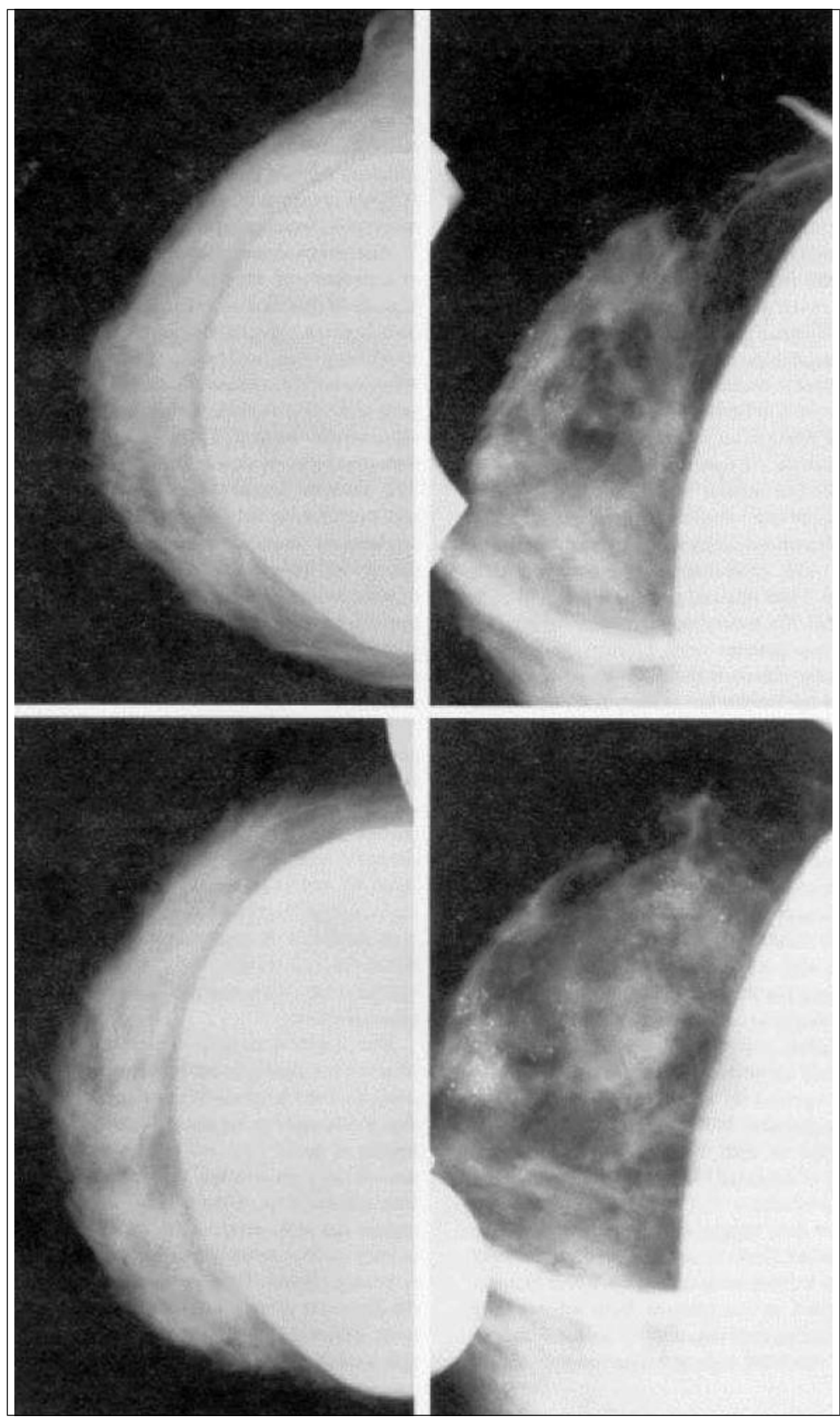

Figure 1) Routine mammogram showing the breast implant and overlying extensive microcalcifications. Craniocaudal views (top left, bottom left); Spot magnification views (top right, bottom right) 
two new areas of concern. Both were removed as lumpectomies. One specimen showed areas of fibrosis and fat necrosis while the other specimen contained intraductal carcinoma with an area of infiltration. The patient has since decided to undergo a modified radical mastectomy.

\section{DISCUSSION}

In our series of seven patients, the average age at implant insertion was 32.4 years (range 25 to 45 years). The average age at cancer detection was 47.8 years (range 42 to 52 years) resulting in a lag time from insertion to cancer detection of 15.4 years (range seven to 25 years). All implants were placed in the subglandular position. Information regarding implant type was available on four patients. Five patients presented with a palpable breast mass, one patient presented with a palpable mass both in the breast and axilla and the final patient had a lesion detected on routine mammography. On microscopic examination, six tumours were infiltrating ductal carcinomas while one tumour was an intraductal carcinoma. Interestingly, the one intraductal lesion was from the only patient whose lesion was detected on routine mammography. An axillary node dissection was performed on all seven patients (case 3 had bilateral lumpectomies and axillary node dissections). Six specimens were negative for malignancy. Of the two patients with positive nodes, one presented with palpable masses in the breast and axilla, while the other patient did not receive her axillary node dissection until five months after her primary surgery, when she presented with an axillary mass. All tumours were noted to be separate from the breast capsule with the exception of one lesion (case 6), which was growing in a stellate fashion along the breast capsule. Histologic sections failed to demonstrate any capsular invasion by the tumour.

Mammograms were performed in four of seven patients. One lesion (case 7) was detected with routine mammography. Mammograms were conducted on one patient (case 1) following presentation with a palpable breast mass. The study was limited due to patient discomfort and inability to fully abduct her arm secondary to capsule contractures. The study was reported as normal, even though a $1.1 \mathrm{~cm}$ infiltrating ductal carcinoma was subsequently removed. In case 3 , a mammogram was reported as normal two months before presentation with a palpable breast mass, and in case 6 a mammogram detected an area of suspicious change in a patient complaining of localized breast pain.

Eleven surgical procedures were performed on the seven patients. There were four lumpectomies and axillary node dissections. One patient (case 2) had a simple mastectomy and later required an axillary node dissection. Three lumpectomies were performed on two patients. Both subsequently went on to a modified radical mastectomy (cases 6 and 7). One patient had a modified radical mastectomy primarily (case 5).

As the age of patients who have undergone augmentation mammaplasty increases, there may be a significant increase in the number of women who develop breast cancer in the presence of mammary implants. Over the last decade, mam- mography has helped to increase greatly the percentage of breast cancers presenting occultly. In our series, only one out of seven women presented with occult disease. Silverstein (12) has shown a false negative rate of $41 \%$ for the mammographic detection of post augmentation breast cancer.

There are several factors contributing to the decreased effectiveness of mammography in the augmented breast. Capsule contractures can cause discomfort when attempting certain views, especially the displacement views as described by Eklund (16). Implant location is a very important issue. Silverstein (1) has shown that the area of breast tissue visualized with displacement mammography in the breast with submuscular implants is decreased by $9 \%$ when compared with preoperative views. This is in contrast to a decrease of $39 \%$ when the implant is in the subglandular position. Breast self-examination may also be easier to perform when the implants are placed deep to the muscle. Implant filling material greatly effects the transmission of x-rays through the implant. Both saline and gel filled implants may significantly impair the ability of the radiologist to interpret mammograms. A recent report (17) highlighted Bio-Oncotic gel as a new implant filler with improved $x$-ray transmission. Further work will be necessary to find even better filler materials.

Surgical treatment of cancer in the augmented breast has paralleled the treatment of cancer in the nonaugmented breast. There has been a growing trend towards less aggressive procedures (wedge resection, axillary node dissection, postoperative radiation). Breast conservation therapy has proved to be an attractive option for both patient and surgeon. Recently, however, a study looking at complications following radiation therapy to an augmented breast showed a very high incidence of capsule contracture in the post-irradiated breast (18). At present, there is no clear consensus as to the optimal surgical treatment of breast cancer in the presence of breast implants.

Firm conclusions cannot be made from a case series report of seven patients. It is our impression, however, that consideration should be given to recommending against augmentation mammaplasty in those women with a strong family history of breast cancer or other significant risk factors. All women who do undergo augmentation should be followed with regular mammograms, performed at a centre that has experience with imaging of the augmented breast. These women are not suitable patients for routine mammographic screening centres. Finally, women should be informed that the detection of occult disease with mammography may be more difficult following augmentation. The prognostic significance of this has yet to be fully determined.

\section{REFERENCES}

1. Silverstein MJ, Handel N, Gamagami P, Waisman E, Gierson ED. Mammographic measurements before and after augmentation mammaplasty. Plast Reconstr Surg 1990;86:1126.

2. Deapen DM, Pike MC, Casagrande JT, Brody GS. The relationship between breast cancer and augmentation mammaplasty:An epidemiologic study. Plast Reconstr Surg 1986;77:361.

3. Brown JB, Fryer MP, Ohlwiler DA. Study and use of synthetic materials, such as silicons and Teflon, as subcutaneous prostheses. Plast Reconst Surg 1961;26:264. 
4. Lilla JA, Vistnes LM. Long-term study of reactions to various silicone breast implants in rabbits. Plast Reconstr Surg 1976;57:637.

5. Berkel H, Birdsell DC, Jenkins H. Breast augmentation: a risk factor for breast cancer? N Engl J Med 1992;326:1649-53.

6. Seidman H, Mushinski MH, Gelb SK, et al. Probabilities of eventually developing or dying of cancer, United States, 1985. CA Cancer J Clin 1985;35:36.

7. Silverstein MJ, Gamagami P, Colburn WJ, et al. Nonpalpable breast lesions: Diagnosis with slightly overpenetrated screen-film mammography and hook wire-directed breast biopsy in 1014 cases. Radiology 1989;171:633.

8. Wanebo HJ, Huvos AG, Urban JA. Treatment of minimal breast cancer. Cancer 1974;33:349.

9. Schwartz GF, Feig SA, Patchefsky AS. Clinicopathologic correlations and significance of clinically occult mammary lesions. Cancer 1978;41:1147.

10. Unzeitig GW, Frankl G, Ackerman M, O'Connell TX. Analysis of the prognosis of minimal and occult breast cancers. Arch Surg 1983;118:1403.

11. Mcgrath MH, Burkhardt BR. The safety and efficacy of breast implants for augmentation mammaplasty. Plast Reconstr Surg 1984;74:550.

12. Silverstein MJ, Gierson ED, Gamagami P, Handel N, Waisman JR. Breast cancer diagnosis and prognosis in women augmented with silicone gel-filled implants. Cancer 1990;66:97.

13. Silverstein MJ, Handel N, Gamagami P, et al. Breast cancer in women after augmentation mammaplasty. Arch Surg 1988;123:681.

14. Leibman AJ, Kruse B. Breast cancer: Mammographic and sonographic findings after augmentation mammaplasty. Radiology 1990;174:195.

15. Heywang SH, Eiermann W, Bassermann R, Fenzl G. Carcinoma of the breast behind a prosthesis - comparison of ultrasound, mammography and MRI. Comput Radiol 1985;9:283.

16. Eklund GW, Busby RC, Miller SH, Job JS. Improved imaging of the augmented breast. Am J Roent 1990;151:469.

17. Beisang AA, Geise RA, Ersek RA. Radiolucent prosthetic gel. Plast Reconstr Surg 1991;87:885.

18. Handel N, Lewinsky B, Silverstein MJ, Gordon P, Zierk K. Conservation therapy for breast cancer following augmentation mammaplasty. Plast Reconstr Surg 1991;87:873. 